\title{
Penerapan Sistem Pendukung Keputusan Dengan Metode Simple Multi Attribute Rating Technique Pada Pemilihan Toko Roti
}

\author{
Erene Gernaria Sihombing ${ }^{1}$, Ester Arisawati ${ }^{1}$, Linda Sari Dewi ${ }^{1 *}$, Frisma Handayanna $^{1}$, Rinawati $^{1}$ \\ ${ }^{I}$ STMIK Nusa Mandiri, Jl. Kramat Raya No.18 Jakarta Pusat
}

\begin{tabular}{l} 
KEYWORDS \\
\hline $\begin{array}{l}\text { Decision Support System, Bakery, SMART, } \\
\text { Pematangsiantar }\end{array}$
\end{tabular}

\section{CORRESPONDENCE}

Phone: 0822-7323-3495

E-mail: erene.egs@nusamandiri.ac.id

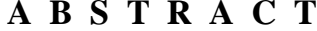

Toko Roti merupakan tempat yang sering dikunjungi masyarakat sebagai tempat membeli roti untuk diberikan sebagai bingkisan atau makanan. Lokasi penelitian di kota pematangsiantar. Banyaknya toko roti yang buka di kota Pematangsiantar membuat konsumen bingung dan membutuhkan informasi yang akurat untuk memutuskan mengunjungi toko roti yang sesuai dengan kebutuhan. Apalagi setiap toko roti memberikan dan menawarkan produk terbaik mereka kepada konsumen. Metode yang digunakan dalam pengambilan keputusan adalah metode SMART (Simple Multi Attribute rating Technique) karena SMART merupakan metode dalam pengambilan keputusan multiatribut. Sistem ini dapat memberikan rekomendasi Toko Roti yang sesuai dengan harapan konsumen untuk menjadi pertimbangan dalam memilih Toko Roti yang tepat, khususnya di kota pematangsiantar yang terdapat 5 Toko Roti yakni: Ganda (A1), Aroma (A2), Francebakery (A3), Valetine (A4) dan Sayangku (A5). Dalam penelitian ini ada 5 kriteria yang mendukung tujuan penelitian yaitu: pelayanan( $\mathrm{C} 1)$, tekstur(C2), cita rasa(C3), harga(C4) dan lokasi(C5). Data penelitian diperoleh dengan cara wawancara dan memberikan kuesioner/angket kepada 250 konsumen. Hasil dari angket diolah dan dihitung menggunakan metode SMART. Berdasarkan hasil penelitian diperoleh ganda (A1) peringkat pertama dengan nilai akhir 0.8835 , francebakery (A3) peringkat 2 dengan nilai akhir 0.5530 dan sayangku (A5) peringkat ketiga dengan nilai akhir 0,45. Diharapkan penelitian ini dapat memberikan masukan kepada konsumen dalam merekomendasikan dan memilih toko roti terbaik di kota pematangsiantar.
\end{abstract}

Bakery is a place frequented by people as a place to buy bread to be given as a gift or food. The number of bakeries that are open in Pematangsiantar city makes consumers confused and need accurate information to decide to visit a bakery that suits their needs. Moreover, every bakery provides and offers their best products to consumers. The method used in decision making is the SMART method (Simple Multi Attribute Rating Technique) because SMART is a method in making multi-attribute decisions. This system can provide recommendations for bakeries that are in accordance with the expectations of consumers to be considered in choosing the right bakery, especially in pematangsiantar city where there are 5 bakeries namely: Double (A1), Aroma (A2), Francebakery (A3), Valetine (A4) and My darling (A5). In this study there are 5 criteria that support the research objectives, namely: service $(C 1)$, texture $(C 2)$, taste $(C 3)$, price (C4) and location (C5). The research data was obtained by interviewing and giving questionnaires / questionnaires to 250 consumers. The results of the questionnaire were processed and calculated using the SMART method. Based on the results of the study, it is obtained double (A1) first rank with the final value of 0.8835 , francebakery (A3) second rank with the final value of 0.5530 and my dear (A5) ranked third with the final value of 0.45 . It is hoped that this research can provide input to consumers in recommending and choosing the best bakery in Pematangsiantar.

\section{PENDAHULUAN}

Toko Roti merupakan tempat yang sering dikunjungi konsumen sebagai tempat membeli roti. Di toko roti para konsumen dimanjakan dan diberi layanan yang memuaskan mereka tanpa membuat mereka repot. Kebanyakan konsumen menggunakan toko roti sebagai tempat untuk membeli roti yang di sukai dan sebagai bingkisan buat orang tersayang dan menjadi trend yang diminati konsumen. Peneliti tertarik melakukan research tentang toko roti terbaik di kota Pematangsiantar berdasarkan pilihan konsumen. Hal ini perlu dilakukan mengingat banyaknya toko roti di kota pematangsiantar yang bermunculan dalam waktu 3 tahun terakhir. Setiap toko roti memberikan dan menawarkan produk unggulan mereka dalam memikat hati konsumen. Hal ini kadang membuat konsumen merasa bingung, apalagi setiap konsumen selalu memperhatikan cita rasa, kualitas bahan, harga, lokasi dan lain-lain. Diharapkan hasil dari penelitian ini dapat memberikan masukan kepada konsumen khususnya masyarakat kota Pematangsiantar dalam memilih toko roti yang memiliki cita rasa yang dapat memanjakan lidah yang sesuai dengan kriteria konsumen. Dalam hal ini peneliti menggunakan teknik wawancara dan angket/kuisioner dalam melakukan penilaian terhadap toko terbaik di kota Pematangsiantar. 
Banyak cabang ilmu komputer yang dapat menyelesaikan permasalahan yang bersifat kompleks. Hal ini terbukti dari penelitian terdahulu oleh para peneliti dalam menyelesaikan permasalahan bidang datamining (Budiharjo \& Muhammad, 2017; Ningsih \& Windarto, 2018; Sudirman, Windarto, \& Wanto, 2018a, 2018b; Supriyadi, Windarto, Soemartono, \& Mungad, 2018; Windarto, 2017b)[5] [8], bidang jaringan saraf tiruan [9][11][12], bidang sistem pendukung keputusan [13]-[17][18]. Berdasarkan penjelasan tersebut, peneliti menggunakan sistem pendukung keputusan untuk dapat menyelesaikan masalah diatas[19], [20]. Sistem pendukung keputusan juga dapat menghindari penilaian subyektifitas yang dihasilkan [13][17], [21], [22].. Penilaian objektifitas sangat diperlukan sehingga sistem pendukung keputusan dapat membantu pihak konsumen dalam merekomendasikan toko roti sesuai dengan kebutuhan konsumen. Dalam hal ini peneliti menggunakan metode SMART (Simple Multi Attribute Rating Technique). Hal ini dikarenakan metode SMART mampu menyelesaikan masalah dengan multikriteria. Ada beberapa penelitian terkait yang menggunakan metode SMART dalam menyelesaikan masalah. Penelitian tersebut dapat dilihat pada tabel berikut ini :

Tabel 1. Penelitian Terkait Metode SMART

\begin{tabular}{ll}
\hline Judul & Resume \\
\hline $\begin{array}{l}\text { Development of } \\
\text { Decision }\end{array}$ & Penelitian ini bertujuan mengembangkan \\
Support System & SPK pada pembelian perumahan, dimana \\
for House & Metode yang digunakan SMART. \\
$\begin{array}{l}\text { Evaluation and } \\
\text { Purchasing[23] }\end{array}$ & $\begin{array}{l}\text { hanya menyediakan atribut perumahan } \\
\text { tetapi juga informasi lingkungan sekitar }\end{array}$ \\
& untuk mengambil keputusan pembelian \\
& perumahan. \\
\hline $\begin{array}{l}\text { Pemilihan } \\
\text { Produk insurans } \\
\text { hayat dengan } \\
\text { metode }\end{array}$ & $\begin{array}{l}\text { Penggunaan teknik SMART melalui } \\
\text { SMART[24] }\end{array}$ \\
\hline
\end{tabular}

Tujuan penelitian ini adalah menganalisa dan menguji apakah metode SMART dapat diterapkan dalam merekomendasikan toko roti terbaik di kota pematangsiantar dimana hasil penelitian dapat memberikan rekomendasi berupa masukan kepada konsumen dalam memilih toko roti terbaik di kota pematangsiantar yang sesuai dengan kebutuhan dan kriteria konsumen.

\section{METODOLOGI PENELITIAN}

\section{A. Kerangka Kerja Penelitian}

Adapun kerangka penelitian yang dibuat sebagai acuan peneliti dalam melakukan penelitian adalah sebagai berikut:

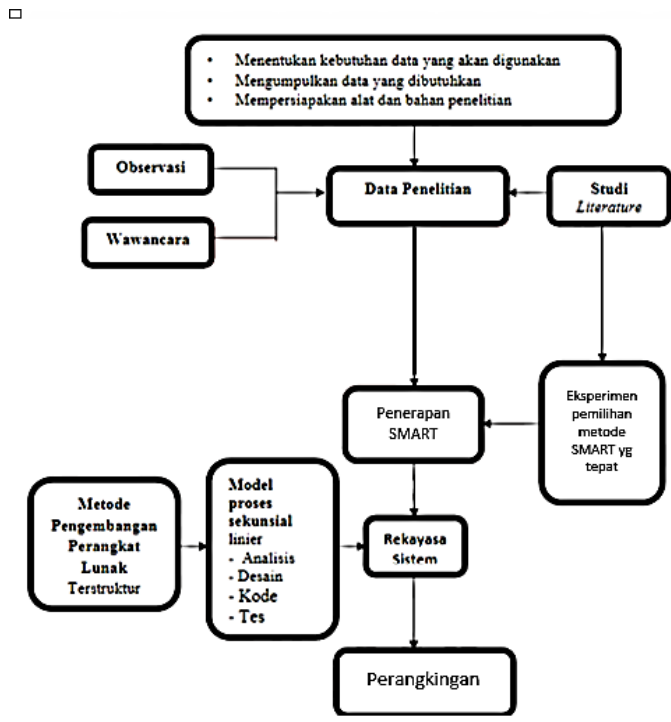

Gambar 1. Kerangka Penelitian

B. Metode Pengumpulan Data

Metode pengumpulan data yang dilakukan yaitu :
a) Dokumentasi
b) Interview (wawancara)
c) Kuesioner
d) Studi Pustaka

C. Metode SMART (Simple Multi Atribute Rating Technique) SMART merupakan suatu model pengambil keputusan yang komprehensif dengan memperhitungkan hal-hal yang bersifat kualitatif dan kuantitatif. Dalam metode ini parameter menjadi penentu keputusan dan memiliki range nilai dan bobot yang berbeda-beda. Nilai tersebut nantinya menjadi penentu keputusan yang diambil [25], [26]. Dalam menyelesaikan permasalahan tersebut, metode SMART memiliki langkah penyelesaian seperti berikut [22], [27], [28]:

1) Menghitung normalisasi kriteria dengan membandingkan nilai bobot kriteria dengan jumlah bobot kriteria, menggunakan rumus:

normalisasi $\mathrm{W}_{\mathrm{j}}=\frac{W_{j}}{\sum_{j=1}^{m} W_{m}}$

pada persamaan (1), $\mathrm{W}_{\mathrm{j}}$ menyatakan normalisasi bobot kriteria ke $\mathrm{j} ; \mathrm{W}_{\mathrm{j}}$, menyatakan nilai bobot dari suatu kriteria; I menyatakan jumlah kriteria dan $\mathrm{W}_{\mathrm{m}}$ dan bobot kriteria ke $\mathrm{m}$

2) Menentukan nilai utility setiap kriteria. Nilai utiliti ini tergantung pada sifat kriteria itu sendiri.

a. Kriteria yang bersifat "lebih diinginkan nilai yang lebih kecil" menggunakan persamaan:

$$
\mathrm{u}_{\mathrm{i}}\left(\mathrm{a}_{\mathrm{i}}\right)=\left(\frac{C_{\max }-C_{\text {out }}}{C_{\max }-c_{\min }}\right) * 100
$$

b. Kriteria yang bersifat "lebih diinginkan nilai yang lebih besar" menggunakan persamaan:

$\mathrm{u}_{\mathrm{i}}\left(\mathrm{a}_{\mathrm{i}}\right)=\left(\frac{C_{\text {out }}-c_{\min }}{C_{\max }-c_{\min }}\right) * 100$

pada persamaan (2) \& (3), $\mathrm{u}_{\mathrm{i}}\left(\mathrm{a}_{\mathrm{i}}\right)$ menyatakan nilai utility kriteria ke I; $\mathrm{C}_{\max }$ menyatakan nilai kriteria maksimal; $\mathrm{C}_{\text {min }}$ menyatakan nilai kriteria minimal dan $\mathrm{C}_{\text {out }}$ menyatakan nilai kriteria ke i.

c. Menghitung nilai akhir menggunakan persamaan: $\mathrm{u}\left(a_{i}\right)=\sum_{j=1}^{m} w_{j} u_{i}\left(a_{i}\right)$ 
pada persamaan (4), $\mathrm{u}\left(a_{i}\right)$ menyatakan nilai total alternatif; $\mathrm{W}_{\mathrm{j}}$ menyatakan nilai pembobotan kriteria ke$\mathrm{j}$ dan $\mathrm{u}_{\mathrm{i}}\left(\mathrm{a}_{\mathrm{i}}\right)$ menyatakan nilai utility kriteria ke-i

\section{HASIL DAN PEMBAHASAN}

Bagian ini menerangkan tahapan dan proses SMART dalam menentukan toko roti terbaik berdasarkan konsumen di kota Pematangsiantar. Penelitian ini menggunakan 5 kriteria penilaian yaitu: Pelayanan(C1), Cita Rasa(C2). Tekstur(C3), Harga (C4) dan Lokasi (C5). Alternatif yang digunakan pada penelitian adalah 5 toko roti terbaik menurut konsumen melalui angket/kuisioner yang diberikan kepada 250 responden. Daftar alternatif toko tersebut adalah Ganda(A1), Aroma(A2), Francebakery(A3), Valetine(A4) dan Sayangku(A5).

Tahap berikutnya adalah memberikan nilai bobot kepada kriteria berdasarkan kepentingan. Dalam hal ini peneliti menggunakan skala persen untuk menentukan bobot seperti yang ditunjukkan pada tabel 2 berikut:

Tabel 2. Nilai Bobot Kriteria

\begin{tabular}{ll}
\hline Kriteria & Bobot \\
\hline Pelayanan & $45 \%$ \\
Cita rasa & $10 \%$ \\
Tekstur & $25 \%$ \\
Harga & $15 \%$ \\
Lokasi & $5 \%$ \\
Total & $\mathbf{1 0 0 \%}$ \\
\hline
\end{tabular}

Berdasarkan tabel 2 dapat dijelaskan pada kasus ini kriteria pelayanan lebih diutamakan dibandingkan cita rasa, tekstur, harga dan lokasi. Untuk kriteria tekstur lebih diutamakan dibandingkan kriteria citra rasa, harga dan lokasi. Untuk kriteria harga menjadi utama dibandingkan cita rasa dan lokasi. Untuk cita rasa lebih diutamakan dibandingkan lokasi.

Setelah pemberian bobot setiap keriteria dilakukan, selanjutnya melakukan normalisasi dengan menggunakan rumus (1) seperti pada tabel 3 berikut:

Tabel 3. Normalisasi Bobot Kriteria

\begin{tabular}{lll}
\hline Kriteria & Bobot & Normalisasi \\
\hline Pelayanan(C1) & 45 & $45 / 100=0.45$ \\
Cita rasa(C2) & 10 & $10 / 100=0.1$ \\
Tekstur(C3) & 25 & $25 / 100=0.25$ \\
Harga(C4) & 15 & $15 / 100=0.15$ \\
Lokasi(C5) & 5 & $5 / 100=0.05$ \\
\hline
\end{tabular}

Normalisasi bobot kriteria yang dilakukan pada tabel 3 digunakan untuk menentukan nilai utility dengan menggunakan data penelitian yang telah diolah dari data kuesioner/angket yang diperoleh seperti yang ditunjukkan pada tabel 4 berikut:

Tabel 4. Data Normalisasi

\begin{tabular}{llllll}
\hline \multirow{2}{*}{ Alternatif } & \multicolumn{5}{c}{ Kriteria } \\
\cline { 2 - 6 } & C1 & C2 & C3 & C4 & C5 \\
\hline Ganda(A1) & 0.81 & 0.62 & 0.77 & 0.68 & 0.56 \\
Aroma(A2) & 0.74 & 0.76 & 0.72 & 0.67 & 0.63 \\
Francebakery(A3) & 0.77 & 0.50 & 0.69 & 0.62 & 0.68 \\
Valentine(A4) & 0.73 & 0.51 & 0.59 & 0.61 & 0.67 \\
Sayangku(A5) & 0.72 & 0.60 & 0.76 & 0.69 & 0.57 \\
\hline Max & $\mathbf{0 . 8 1}$ & $\mathbf{0 . 7 6}$ & $\mathbf{0 . 7 7}$ & $\mathbf{0 . 6 9}$ & $\mathbf{0 . 6 8}$ \\
\hline Min & $\mathbf{0 . 7 2}$ & $\mathbf{0 . 5 0}$ & $\mathbf{0 . 5 9}$ & $\mathbf{0 . 6 1}$ & $\mathbf{0 . 5 6}$ \\
\hline
\end{tabular}

Dengan menggunakan data tabel 4 , nilai utility akan dihitung berdasarkan sifat masing-masing kriteria. Sifat ini ditentukan berdasarkan penelitian yang dilakukan.

Tabel 5. Sifat masing-masing kriteria

\begin{tabular}{ll}
\hline Kriteria & Sifat Kriteria \\
\hline Pelayanan & Lebih cepat lebih baik \\
Cita rasa & Lebih lengkap lebih baik \\
Tekstur & Lebih lengkap lebih bagus \\
Harga & Lebih murah lebih bagus \\
Lokasi & Lebih cepat lebih baik \\
\hline
\end{tabular}

Berdasarkan tabel 5 nilai utility pelayanan, Cita rasa, Tekstur, Harga, Lokasi untuk masing-masing alternatif dapat dihitung seperti berikut:

Nilai Pelayanan dihitung dengan persamaan (3)

Max Pelayanan $(\mathrm{C} 1)=0,81$

Min Pelayanan $(\mathrm{C} 1)=0,72$

A1 $($ Pelayanan $)=\left(\frac{0.81-0.72}{0.81-0.72}\right) * 100 \%=1$

A2 $($ Pelayanan $)=\left(\frac{0.74-0.72}{0.81-0.72}\right) * 100 \%=0.22$

A3 (Pelayanan $)=\left(\frac{0.77-0.72}{0.81-0.72}\right) * 100 \%=0.55$

A4 (Pelayanan $)=\left(\frac{0.73-0.72}{0.81-0.72}\right) * 100 \%=0.11$

A5 $($ Pelayanan $)=\left(\frac{0.72-0.72}{0.81-0.72}\right) * 100 \%=0$

Nilai Cita rasa dihitung dengan persamaan (3)

Max Cita $\operatorname{rasa}(\mathrm{C} 2)=0.76$

Min Cita $\operatorname{rasa}(\mathrm{C} 2)=0.50$

$\mathrm{A} 1($ Cita rasa $)=\left(\frac{0.76-0.62}{0.76-0.50}\right) * 100 \%=0.53$

$\mathrm{A} 2($ Cita rasa $)=\left(\frac{0.76-0.76}{0.76-0.50}\right) * 100 \%=0$

A $3($ Cita rasa $)=\left(\frac{0.76-0.50}{0.76-0.50}\right) * 100 \%=1$

$\mathrm{A} 4($ Cita rasa $)=\left(\frac{0.76-0.51}{0.76-0.50}\right) * 100 \%=0.96$

A5 $($ Cita rasa $)=\left(\frac{0.76-0.51}{0.76-0.50}\right) * 100 \%=0.61$

Nillai Produk dihitung dengan persamaan (3)

Max Tekstur(C3) $=0.77$

Min Tekstur(C3) $=0.59$

$\mathrm{A} 1$ (Tekstur) $=\left(\frac{0.77-0.59}{0.77-0.59}\right) * 100 \%=1$

A2 (Tekstur) $=\left(\frac{0.72-0.59}{0.77-0.59}\right) * 100 \%=0.72$

A3 (Tekstur) $=\left(\frac{0.69-0.59}{0.77-0.59}\right) * 100 \%=0.55$

$\mathrm{A} 4$ (Tekstur) $=\left(\frac{0.59-0.59}{0.77-0.59}\right) * 100 \%=0$

A5 (Tekstur) $=\left(\frac{0.76-0.59}{0.77-0.59}\right) * 100 \%=0.94$

Nilai Harga dihitung dengan persamaan (3)

Max Harga $(C 4)=0.69$

Min Harga $(C 4)=0.61$

A $1($ Harga $)=\left(\frac{0.68-0.61}{0.69-0.61}\right) * 100 \%=0.87$

$\mathrm{A} 2(\mathrm{Harga})=\left(\frac{0.67-0.61}{0.69-0.61}\right) * 100 \%=0.75$

A3 $($ Harga $)=\left(\frac{0.62-0.61}{0.69-0.61}\right) * 100 \%=0.12$

A4 $($ Harga $)=\left(\frac{0.61-0.61}{0.69-0.61}\right) * 100 \%=0$

A5 $($ Harga $)=\left(\frac{0.69-0.61}{0.69-0.61}\right) * 100 \%=1$

Nilai Lokasi dihitung dengan persamaan (3)

Max Lokasi $($ C5 $)=0.68$

Min Lokasi $(\mathrm{C} 5)=0.56$

$\mathrm{A} 1$ (Lokasi) $=\left(\frac{0.56-0.56}{0.68-0.56}\right) * 100 \%=0$

A2 $($ Lokasi $)=\left(\frac{0.63-0.56}{0.68-0.56}\right) * 100 \%=0.58$ 


$$
\begin{aligned}
& \text { A3 (Lokasi) }=\left(\frac{0.68-0.56}{0.68-0.56}\right) * 100 \%=1 \\
& \text { A4 (Lokasi) }=\left(\frac{0.67-0.56}{0.68-0.56}\right) * 100 \%=0.91 \\
& \text { A5 (Lokasi) }=\left(\frac{0.57-0.56}{0.68-0.56}\right) * 100 \%=0.08
\end{aligned}
$$

Berikut ini hasil lengkap matrik perhitungan nilai utility seperti yang ditunjukkan tabel 6 berikut:

Tabel 6. Matriks nilai utility alternatif

\begin{tabular}{llllll}
\hline \multirow{1}{*}{ Alternatif } & \multicolumn{5}{c}{ Kriteria } \\
\cline { 2 - 6 } & \multicolumn{1}{c}{ C1 } & \multicolumn{1}{c}{ C2 } & \multicolumn{1}{c}{ C3 } & C4 & \multicolumn{1}{c}{ C5 } \\
\hline Ganda(A1) & 1 & 0.53 & 1 & 0.87 & 0 \\
Aroma(A2) & 0.22 & 0 & 0.72 & 0.75 & 0.58 \\
Francebakery(A3) & 0.55 & 1 & 0.55 & 0.12 & 1 \\
Valentine(A4) & 0.11 & 0.96 & 0 & 0 & 0.91 \\
Sayangku(A5) & 0 & 0.61 & 0.94 & 1 & 0.08 \\
\hline
\end{tabular}

Setelah diperoleh nilai utility seperti tabel 6, langkah terakhir adalah menghitung nilai akhir dengan menggunakan rumus (4) berikut:

Ganda - A1 (Pelayanan $)=1 * 0.45=0.45$

Ganda $-\mathrm{A} 1($ Cita rasa $)=0.53 * 0.1=0.053$

Ganda $-\mathrm{A} 1$ (Tekstur) $=1 * 0.25=0.25$

Ganda $-\mathrm{A} 1$ (Harga) $=0.87 * 0.15=0.1305$

Ganda $-\mathrm{A} 1$ (Lokasi) $=0 * 0.05=0$

Aroma - A2 $($ Pelayanan $)=0.22 * 0.45=0.099$

Aroma $-\mathrm{A} 2($ Cita rasa $)=0 * 0.1=0$

Aroma $-\mathrm{A} 2$ (Tektur) $=0.72 * 0.25=0.18$

Aroma $-\mathrm{A} 2($ Harga $)=0.75 * 0.15=0.1125$

Aroma $-\mathrm{A} 2($ Lokasi $)=0.58 * 0.05=0.029$

France $-\mathrm{A} 3($ Pelayanan $)=0.55 * 0.45=0.2475$

France $-\mathrm{A} 3($ Cita rasa $)=1 * 0.1=0.1$

France $-\mathrm{A} 3($ Tekstur $)=0.55 * 0.25=0.1375$

France $-\mathrm{A} 3$ (Harga) $=0.12 * 0.15=0.18$

France $-\mathrm{A} 3($ Lokasi $)=1 * 0.05=0.05$

Valentine - A4 (Pelayanan) $=0.1 * 0.45=0.045$

Valentine - A4 $($ Cita rasa $)=0.96 * 0.1=0.096$

Valentine $-\mathrm{A} 4$ (Teksur) $=0 * 0.25=0$

Valentine $-\mathrm{A} 4$ (Harga) $=0 * 0.15=0$

Valentine $-\mathrm{A} 4$ (Lokasi) $=0.91 * 0.05=0.045$

Sayangku - A5 (Pelayanan $)=0 * 0.45=0$

Sayangku - A5 $($ Cita rasa $)=0.61 * 0.1=0.061$

Sayangku - A5 $($ Tekstur $)=0.94 * 0.25=0.235$

Sayangku $-\mathrm{A} 5$ (Harga) $=1 * 0.15=0.15$

Sayangku - A5 $($ Lokasi $)=0.08 * 0.05=0.004$

\begin{tabular}{|c|c|c|c|c|c|c|}
\hline \multirow[t]{2}{*}{ Alt } & \multicolumn{5}{|c|}{ Kriteria } & \multirow{2}{*}{$\begin{array}{l}\text { Nilai } \\
\text { Akhir }\end{array}$} \\
\hline & C1 & $\mathrm{C2}$ & $\mathrm{C3}$ & C4 & C5 & \\
\hline A1 & 0.45 & 0.053 & 0.25 & 0.1305 & 0 & 0.8835 \\
\hline A2 & 0.099 & 0 & 0.18 & 0.1125 & 0.029 & 0.4205 \\
\hline A3 & 0.2475 & 0.1 & 0.1375 & 0.018 & 0.05 & 0.553 \\
\hline A4 & 0.045 & 0.096 & 0 & 0 & 0.045 & 0.186 \\
\hline A5 & 0 & 0.061 & 0.235 & 0.15 & 0.004 & 0.45 \\
\hline
\end{tabular}

Berikut ini hasil lengkap perhitungan metode SMART

Tabel 7. Hasil Nilai Akhir

Berdasarkan tabel 7, dapat dijelaskan bahwa proses perangkingan dilakukan dengan melihat hasil dari nilai tertinggi. Berdasarkan hasil tersebut, alternatif A1 (Ganda) 0.8835 menjadi rangking 1, alternatif A3 (Francebakery) 0.5530 menjadi rangking 2 dan A5 (Sayangku) 0,45 menjadi rangking 3 .

\section{KESIMPULAN}

Berdasarkan hasil penelitian dapat disimpulkan beberapa hal:

a. Pemilihan toko roti terbaik berdasarkan konsumen di kota Pematangsiantar dengan menggunakan metode SMART cukup efektif dan dapat diterapkan dengan 5 kriteria penilaian yang digunakan: pelayanan (C1), cita rasa (C2), tekstur (C3), harga (C4), lokasi (C5) dan 5 alternatif pilihan: Ganda (A1), Aroma (A2), Francebakery (A3), Valetine (A4) dan Sayangku (A5).

b. Berdasarkan hasil penelitian diperoleh Ganda (A1) dengan nilai akhir 0.8835 sebagai peringkat pertama, Francebakery (A3) dengan nilai akhir 0.5530 sebagai peringkat kedua dan Sayangku (A5) dengan nilai akhir 0,45 sebagai peringkat ketiga.

\section{DAFTAR PUSTAKA}

[1] B. Supriyadi, A. P. Windarto, T. Soemartono, and Mungad, "Classification of natural disaster prone areas in Indonesia using K-means," Int. J. Grid Distrib. Comput., vol. 11, no. 8, pp. 87-98, 2018.

[2] A. P. W. Budiharjo and A. Muhammad, "Comparison of Weighted Sum Model and Multi Attribute Decision Making Weighted Product Methods in Selecting the Best Elementary School in Indonesia," Int. J. Softw. Eng. Its Appl., vol. 11, no. 4, pp. 69-90, 2017.

[3] S. Sudirman, A. P. Windarto, and A. Wanto, "Data Mining Tools | RapidMiner: K-Means Method on Clustering of Rice Crops by Province as Efforts to Stabilize Food Crops In Indonesia," IOP Conf. Ser. Mater. Sci. Eng., vol. 420, no. 12089, pp. 1-8, 2018.

[4] M. G. Sadewo, A. P. Windarto, and S. R. Andani, "Pemanfaatan Algoritma Clushtering Dalam Mengelompokkan Jumlah Desa / Kelurahan Yang Memiliki Sarana Kesehatan,” vol. I, pp. 124-131, 2017.

[5] A. P. Windarto, "Penerapan Data Mining Pada Ekspor Buah-Buahan Menurut Negara Tujuan Menggunakan KMeans Clustering," Techno.COM, vol. 16, no. 4, pp. 348-357, 2017.

[6] Sudirman, A. P. Windarto, and A. Wanto, "Data mining tools | rapidminer: K-means method on clustering of rice crops by province as efforts to stabilize food crops in Indonesia," IOP Conf. Ser. Mater. Sci. Eng., vol. 420, p. 12089, 2018.

[7] S. R. Ningsih and A. P. Windarto, "Penerapan Metode Promethee II Pada Dosen Penerima Hibah P2M Internal," InfoTekJar (Jurnal Nas. Inform. dan Teknol. Jaringan), vol. 3, no. 1, pp. 20-25, 2018.

[8] A. P. Windarto, "Implementation of Data Mining on Rice Imports by Major Country of Origin Using Algorithm Using K-Means Clustering Method," Int. J. Artif. Intell. Res., vol. 1, no. 2, pp. 26-33, 2017.

A. P. Windarto, L. S. Dewi, and D. Hartama, "Implementation of Artificial Intelligence in Predicting the Value of Indonesian Oil and Gas Exports With BP Algorithm," Int. J. Recent Trends Eng. Res., vol. 3, no. 10, pp. 1-12, 2017.

A. P. Windarto, M. R. Lubis, and Solikhun, "MODEL ARSITEKTUR NEURAL NETWORK DENGAN BACKPROPOGATION PADA PREDIKSI TOTAL LABA RUGI KOMPREHENSIF BANK UMUM KONVENSIONAL," Kumpul. J. Ilmu Komput., vol. 5, no. 2, pp. 147-158, 2018.

[11] A. P. Windarto, M. R. Lubis, and Solikhun, "IMPLEMENTASI JST PADA PREDIKSI TOTAL LABA RUGI KOMPREHENSIF BANK UMUM 
KONVENSIONAL

DENGAN

BACKPROPAGATION," J. Teknol. Inf. dan Ilmu Komput., vol. 5, no. 4, pp. 411-418, 2018.

[12] M. N. H. Siregar, "Neural Network Analysis With Backpropogation In Predicting Human Development Index ( HDI ) Component by Regency / City In North Sumatera,"Internation al Jo urnal OfI $n$ for m a ti o $n S$ yst e $m$ Te c h no logy, vol. 1, no. 1, pp. 22-33, 2017.

[13] A. P. WINDARTO, "Implementasi metode topsis dan saw dalam memberikan reward pelanggan," Kumpul. J. Ilmu Komput., vol. 4, no. 1, pp. 88-101, 2017.

[14] D. R. Sari, A. P. Windarto, D. Hartama, and S. Solikhun, "Sistem Pendukung Keputusan untuk Rekomendasi Kelulusan Sidang Skripsi Menggunakan Metode AHPTOPSIS," J. Teknol. dan Sist. Komput., vol. 6, no. 1, p. 1,2018 .

[15] F. Adelia, D. Wahyuli, T. Imanda, and A. P. Windato, "Analisis Promethee II Pada Faktor Penyebab Mahasiswa Sulit Menemukan Judul Artikel Ilmiah," Jurnal Ilmiah KOMPUTASI, vol. 17, no. 2, pp. 131-135, 2018.

[16] T. Imandasari, A. Wanto, and A. P. Windarto, "Analisis Pengambilan Keputusan Dalam Menentukan Mahasiswa PKL Menggunakan Metode PROMETHEE," J. Ris. Komput., vol. 5, no. 3, pp. 234 239, 2018.

[17] A. P. Windarto, "Penilaian Prestasi Kerja Karyawan PTPN III Pematangsiantar Dengan Metode Simple Additive Weighting (SAW)," J. Ris. Sist. Inf. Dan Tek. Inform., vol. 2, no. ISSN 2527-5771, pp. 84-95, 2017.

[18] A. Putrama and A. P. Windarto, "Analisis dalam menentukan produk bri syariah terbaik berdasarkan dana pihak ketiga menggunakan ahp," CESS (Journal Comput. Eng. Syst. Sci., vol. 3, no. 1, pp. 60-64, 2018.

[19] M. S. Abdillah, "Sistem Pendukung Keputusan Pembelian Notebook," Jurnal Informatika Mulawarman, 2011.

[20] H. Imtiyaz, B. H. Prasetio, and N. Hidayat, "Sistem Pendukung Keputusan Budidaya Tanaman Cabai Berdasarkan Prediksi Curah Hujan," J. Pengemb. Teknol. Inf. dan Ilmu Komput., vol. 1, no. 9, pp. 733 738, 2017.

[21] A. Yusnita, R. Handini, P. Keputusan, L. Rumah, and M. Yang, "SISTEM PENDUKUNG KEPUTUSAN MENENTUKKAN LOKASI UMAH MAKAN YANG STRATEGIS MENGGUNAKAN METODE NAIVE BAYES," Semin. Nas. Teknol. Inf. Komun. Terap. 2012, vol. 2012, no. Semantik, pp. 290-294, 2012.

[22] Y. Purnamasari, T. H. Pudjiantoro, and D. Nursantika, "SISTEM PENILAIAN KINERJA DOSEN TELADAN MENGGUNAKAN METODE SIMPLE MULTY ATTRIBUTE RATING TECHNIQUE (SMART)," $J$. Teknol. Elektro, Univ. Mercu Buana, vol. 8, no. 1, pp. 16-23, 2017.

[23] C. Hsu, J. Goh, and P. Chang, "Development of Decision Support System for House Evaluation and Purchasing," World Acad. Sci., vol. 6, no. 5, pp. 572-577, 2012.

[24] M. Bahari, N. M. A. T. Ali, and S. A. U. H. Nee, "Pemilihan produk insurans hayat dengan menggunakan," Semin. Kebangs. Sains Kuantitatif, pp. 19-21, 2006.

[25] Suryanto and M. Safrizal, "Sistem Pendukung Keputusan Pemilihan Karyawan Teladan dengan Metode SMART (Simple Multi Attribute Rating Technique)," J. CoreIT, vol. 1, no. 2, pp. 25-29, 2015.

[26] E. Yulianti, "SISTEM PENDUKUNG KEPUTUSANPEMILIHAN MOBIL DENGAN METODA SIMPLE MULTY ATTRIBUTE RATING (SMART)," J. Momentum, vol. 17, no. 1, pp. 55-59,
2015.

[27] A. S. Honggowibowo, "Sistem Pendukung Keputusan Penerimaan Calon Teknologi Adisutjipto Menggunakan Simple Multi Attribute Rating Technique," J. angkasa, vol. VII, no. 2, pp. 31-38, 2015.

[28] Diana, "KELAYAKAN BISNIS MENERAPKAN SIMPLE MULTI ATTRIBUTE RATING TECHNIQUE ( SMART )," J. Ilm. MATRIK, vol. 18, no. 2, pp. 113-124, 2016. 